\title{
Human Motion Monitoring Based on Carbon Nanotube Flexible Strain Sensor
}

\author{
Linfei Qiu \\ Foundation Department, Hangzhou Polytechnic, Hangzhou, 310000, China \\ E-mail: qlf118827@163.com
}

Received: 15 May 2021/ Accepted: 21 September 2021 / Published: 10 October 2021

\begin{abstract}
Aiming at the problems of traditional methods such as hysteresis, low accuracy of monitoring results, low motion recognition rate and poor sensitivity, a human motion monitoring method based on carbon nanotube flexible strain sensors is proposed. To realize human motion monitoring, first, the carbon nanotube flexible strain sensor is configured to obtain its performance parameters; Secondly, the human body motion acceleration data is collected through the window processing method, and the preprocessing is performed to filter out the noise data; A feature extraction model of human motion posture is established based on the data preprocessing results, which is used to extract human motion posture; Finally, by establishing a position model of human body motion node based on the carbon nanotube flexible strain sensor, the monitoring of human body motion is realized. The experimental results show that the proposed method has high accuracy (up to 90\%), excellent recognition rate, with the maximum sensitivity coefficient close to the optimal value of 1.0 , indicating practical application value.
\end{abstract}

Keywords: carbon nanotube flexible strain sensor; motion monitoring; motion acceleration data; sensitivity

\section{$\underline{\text { FULL TEXT }}$}

(C) 2021 The Authors. Published by ESG (www.electrochemsci.org). This article is an open access article distributed under the terms and conditions of the Creative Commons Attribution license (http://creativecommons.org/licenses/by/4.0/). 